Article

\title{
Experimental Research into the Evolution of Permeability in a Broken Coal Mass under Cyclic Loading and Unloading Conditions
}

\author{
Bo Li ${ }^{1,2}$, Quanle Zou ${ }^{1,2, *}$ and Yunpei Liang ${ }^{1,2, *}$ \\ 1 State Key Laboratory of Coal Mine Disaster Dynamics and Control, Chongqing University, \\ Chongqing 400044, China; libo967810@163.com \\ 2 College of Resources and Environment Science, Chongqing University, Chongqing 400044, China \\ * Correspondence: quanlezou2016@cqu.edu.cn (Q.Z.); liangyunpei@cqu.edu.cn (Y.L.); \\ Tel.: +86-177-8337-2719 (Q.Z.); +86-135-9460-8029 (Y.L.)
}

Received: 28 December 2018; Accepted: 19 February 2019; Published: 21 February 2019

\begin{abstract}
The permeability characteristics of a broken coal mass under repeated loading and unloading conditions exert significance on spontaneous combustion of coal in goaf during the mining of coal seam groups. Considering this, by using the seepage test system for broken coal-rock mass, seepage tests under cyclic loading and unloading conditions, were carried out on broken coal masses. The test results show that the fitting curves between permeability and effective stress, strain and porosity are a logarithmic function, cubic function and power function, respectively. Besides, the permeability of a broken coal sample under cyclic loading and unloading conditions is determined by its porosity, which conforms to the cubic law. With increased cyclic loading and unloading times, the permeability loss, stress sensitivity and the crushing amount of the broken coal sample were gradually reduced, but the particle size gradation of the broken coal sample gradually became better. During one loading and unloading cycle, the stress sensitivity of the permeability of coal samples in the loading stage was far higher than that in the unloading stage. In the loading stage, the re-arrangement, breakage and compressive deformation of coal particles can lead to a reduction in porosity, consequently resulting in a decreased permeability. In the unloading stage, only the permeability reduction of coal samples due to particle deformation can be recovered.
\end{abstract}

Keywords: broken coal mass; cyclic loading and unloading; goaf; seepage

\section{Introduction}

Coal spontaneous combustion (CSC) threatens the safety and production of coal mines and it often causes great economic loss, casualties and large-scale environmental pollution [1-3]. Goaf is easily subjected to CSC, which occurs due to the autothermal reaction between broken coal masses and air [4-6]. There are many factors influencing the CSC in goaf, involving internal and external factors [7]. Among various factors, air leaking from the working face is the main factor triggering fire in the goaf, which depends on the permeability of the broken coal-rock mass in goaf [8,9]. Therefore, investigating the permeability characteristics of broken coal-rock mass during compaction is important when trying to prevent CSC in goaf. When multiple coal seams are present in mines, the stress and permeability of goaf are disturbed again during the mining of subsequent coal seams [10-12]. Repeated loading and unloading cause further breakage of broken coal-rock masses in goaf, resulting in changes in porosity and permeability, therefore, the evolution of the permeability of a broken coal-rock mass in goaf during the mining of coal seam groups differs from that during the mining of a single coal seam. It is necessary to explore the evolution of permeability of broken coal-rock masses under cyclic loading and unloading conditions. 
However, goaf is an enclosed space with complex and unknown environments and therefore it is extremely dangerous to measure directly the permeability of broken coal masses in goaf; such a task is also expensive [13-18]. In current research, the permeability of coal masses in goaf is generally indirectly evaluated by establishing the prediction model for permeability of coal masses in goaf based on theoretical analysis, numerical simulation and laboratory trials [19-23]. Jozefowicz [24] acquired the empirical formula for the permeability of coal masses in goaf by fitting the experimental data of permeability of rocks in the post-peak failure zone under different stresses. Li and Logan [25] obtained a simple model to predict the permeability of coal masses in goaf based on Carman-Kozeny (C-K) and Happel (H) equations. Supposing that particles of broken rock masses are cuboidal, Fan and Liu [26] proposed a theoretical calculation model for permeability of broken rock masses based on elastic theory. Karacan [27] proposed a model for fractal porous media, which is used for predicting the porosity and permeability of goaf as well as the air leakage in goaf. Chu et al. [28] experimentally investigated the evolution of strain, porosity and permeability of broken coal samples of different particle sizes, under different stresses and various temperatures. Zhang et al. [29] investigated the evolution of permeability of broken coal-rock mass and its influencing factors during the repeated mining of coal seam groups. Based on Hertzian contact deformation, the deformation of broken coal particles was evaluated. By conducting water seepage tests on broken rock masses, Ma et al. [30] concluded that the water seepage from a broken rock mass is non-Darcian. After carrying out seepage tests on sandstones with different porosities, Miao et al. [31] suggested that different porosities correspond to different non-Darcian coefficients. By utilising a self-designed test system for gas seepage, Li et al. [32] investigated the relationship between the porosity and permeability of broken coal mass under different gas pressures and continuously measured the gas pressures and flow velocities therein.

The aforementioned research concentrates on the permeability characteristics of broken coal-rock mass during compaction while rarely reporting on the permeability characteristics of broken coal-rock masses under cyclic loading and unloading conditions. Therefore, in this work, by applying a seepage test system for damaged coal-rock masses, seepage tests were carried out on the broken coal mass under cyclic loading and unloading conditions. First of all, the permeability evolution law of broken coal samples under cyclic loading and unloading conditions was obtained, and the sensitivity of permeability of broken coal samples was also analysed. Afterwards, the particle breakage and distribution law after each loading and unloading seepage test was analysed. Finally, the reasons for the changes in permeability of broken coal samples under cyclic loading and unloading conditions were revealed, and the relationship between permeability and strain, and porosity under cyclic loading and unloading conditions was discussed. The research results provide important guidance to those seeking to prevent spontaneous combustion of coal in goaf during the mining of coal seam groups.

\section{Experiments}

\subsection{Collection and Preparation of Coal Samples}

Coal samples were taken from the \#11-2 coal seam in 121109 working face of Xinji No. 2 Coal Mine in Huainan, Anhui Province, China, as shown in Figure 1a. The result of proximate analysis of coal samples through is shown in Table 1. Large raw coal samples, taken from the working face, were artificially crushed into mixed coal samples with different particle sizes. Afterwards, the coal samples with a particle size of $15.1-18.2 \mathrm{~mm}$ were obtained by mechanical sifters. The specific treatment process is displayed in Figure $1 b$. 
(a)

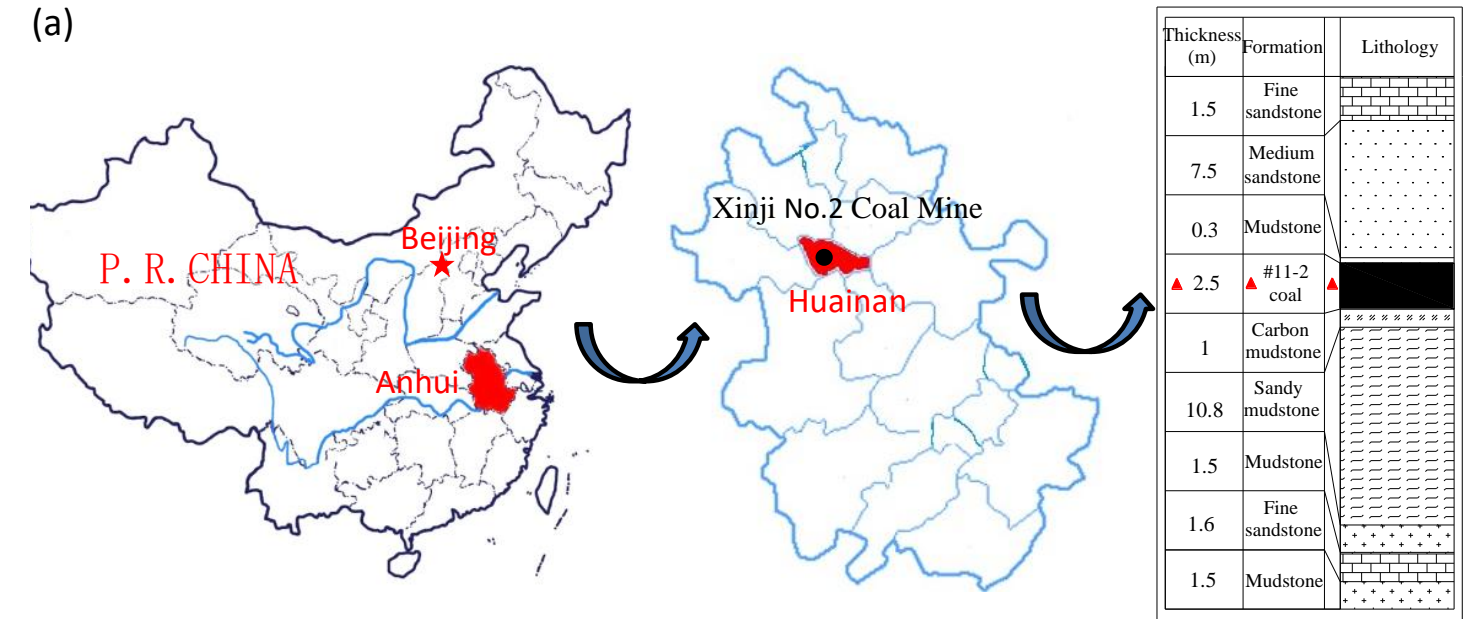

(b)

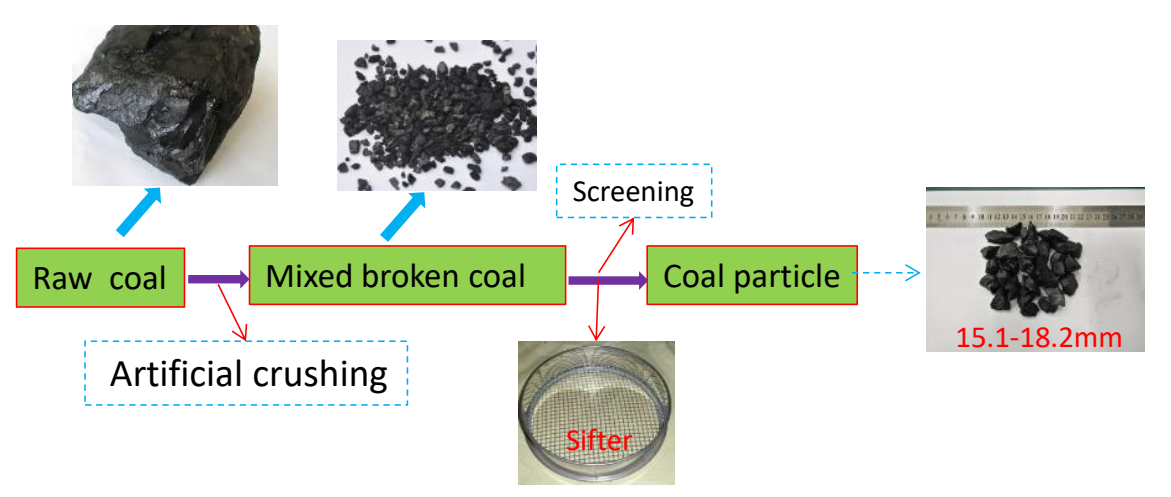

Figure 1. Collection site of coal samples and the process of preparing broken coal samples. (a) Sample collection site; (b) The process of preparing broken coal samples.

Table 1. Results of proximate analysis of coal samples.

\begin{tabular}{cccc}
\hline $\begin{array}{c}\text { Air Dry Basis Moisture } \\
(\text { Mad }) / \%\end{array}$ & $\begin{array}{c}\text { Air Dry Basis Ash } \\
(\text { Aad }) / \%\end{array}$ & $\begin{array}{c}\text { Air Dry Basis Volatiles } \\
(\text { Vad }) / \%\end{array}$ & $\begin{array}{c}\text { Actual Density } \\
(\rho) /\left(\mathrm{g} / \mathrm{cm}^{3}\right)\end{array}$ \\
\hline 2.01 & 23.67 & 32.06 & 1.43 \\
\hline
\end{tabular}

\subsection{Experimental Devices and Test Schemes}

The seepage test system for damaged coal-rock mass was applied and the schematic diagram of axial seepage in the system is shown in Figure 2. The coal sample was placed in the colloid sleeve, and the colloid sleeve was installed in the hydraulic chamber of the high-pressure kettle. The diameter of the colloid sleeve was $5 \mathrm{~cm}$, with the maximum height of the colloid sleeve as $10 \mathrm{~cm}$. The maximum vertical loading strength was $70 \mathrm{MPa}$, with the accuracy as $0.01 \mathrm{MPa}$. The maximum confining pressure was $25 \mathrm{MPa}$, with the accuracy as $0.1 \mathrm{MPa}$.

During the experiment, triaxial seepage testing was conducted using nitrogen (at a pressure of $0.05 \mathrm{MPa})$ at normal temperature $\left(25^{\circ} \mathrm{C}\right)$, at which the nitrogen density was $1.25 \mathrm{~kg} / \mathrm{m}^{3}$ and its dynamic viscosity was $1.76 \times 10^{-5} \mathrm{~Pa} / \mathrm{s}^{-1}$. The axial stress and confining pressure were synchronously applied to the samples and the axial stress was equal to the confining pressure. The stress path is shown in Figure 3. The specific experimental steps are shown as follows:

1. Firstly, the broken coal mass was weighed and its mass recorded. Afterwards, the colloid sleeve was put into the high-pressure kettle and then the perforated plate and the metal screen were successively placed into the lower part of the colloid sleeve. Then, the weighed broken coal mass was put into the colloid sleeve to be shaken and compacted in order that the upper surfaces of broken coal samples in the colloid sleeve were smooth at the same horizontal plane. Moreover, the initial 
height $\left(h_{0}\right)$ of broken coal samples in the colloid sleeve was measured using Vernier callipers and this height recorded. Finally, the perforated plate and the metal screen were successively put into the upper part of broken coal samples so that the test specimen was fully installed. The purpose of placing the perforated plate and the metal screen at the upper and lower parts of the colloid sleeve was to prevent pulverised coal carried by the flowing gas from blocking the gas pipeline during seepage testing.

2. The other parts of the apparatus were installed and then the seepage test was carried out according to the stress path shown in Figure 3.

3. After finishing the test, the broken coal samples were taken out and screened using mechanical sifters. Afterwards, the screened coal samples with different particle sizes were weighed and the masses recorded.

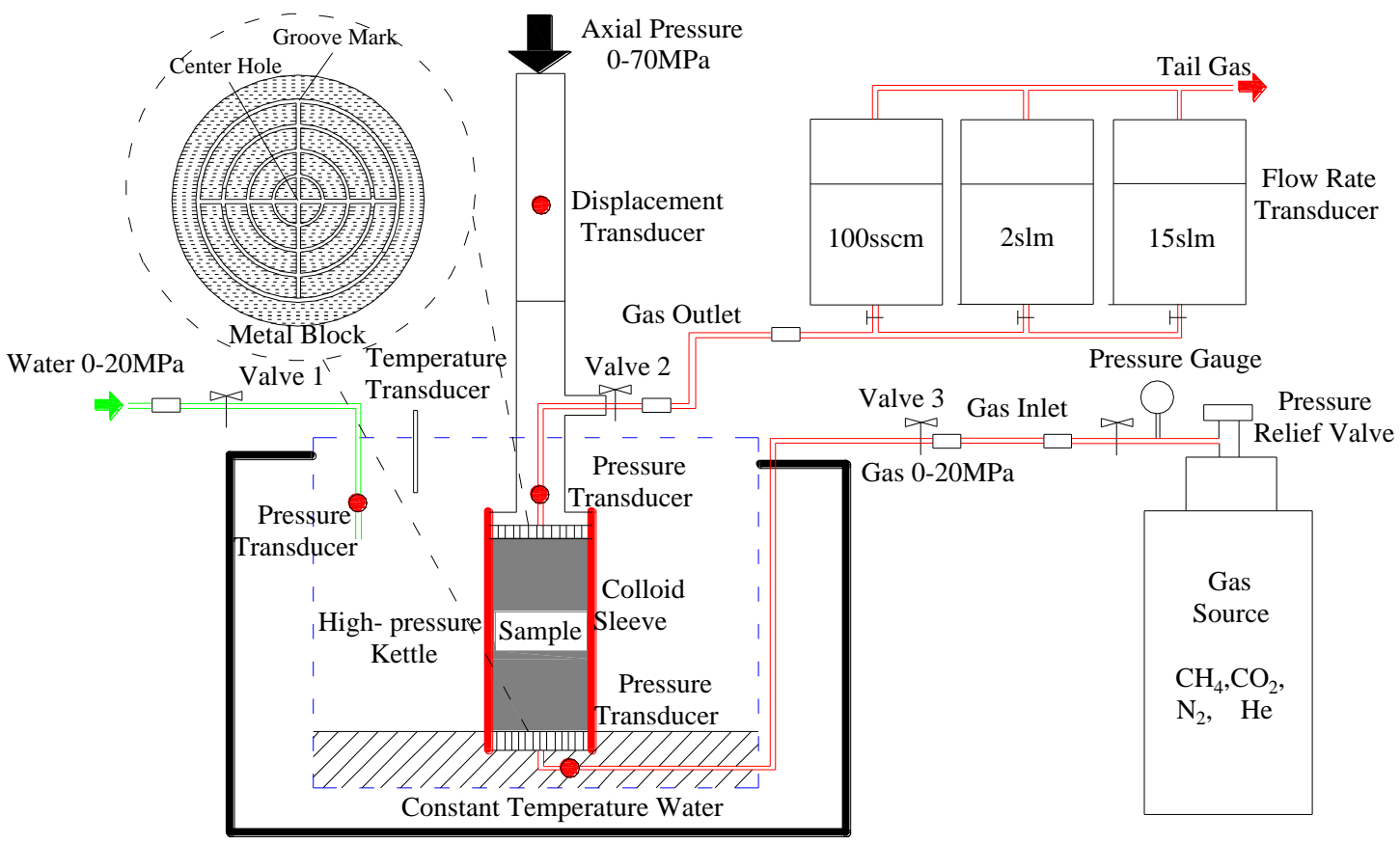

Figure 2. Schematic diagram of the seepage test system for damaged coal-rock masses.

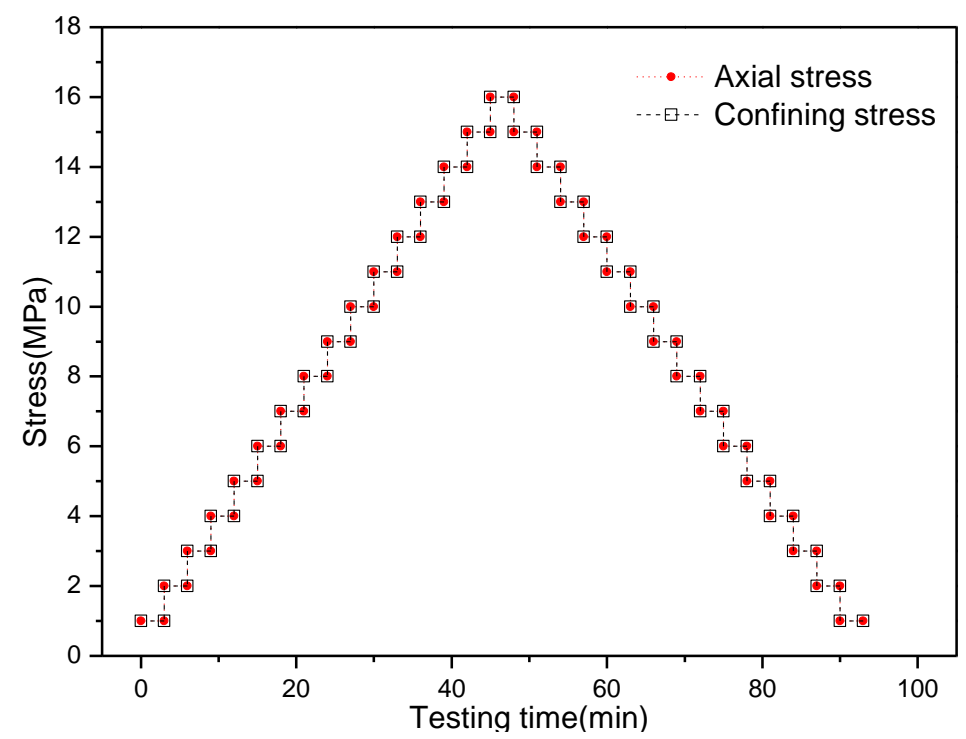

Figure 3. Stress path during each loading and unloading cycle. 


\section{Test Results}

\subsection{Permeability of Broken Coal Samples under Cyclic Loading and Unloading Conditions}

During the experiment, it was supposed that the nitrogen flow in broken coal samples conformed to Darcy's law and then the permeability of coal samples was calculated according to various parameters including the flow of coal samples and gas pressures on two ends of coal samples, which can be expressed as follows:

$$
K=\frac{2 P_{0} Q_{0} \mu L}{A\left(P_{1}^{2}-P_{2}^{2}\right)}
$$

where $K$ is the permeability of the coal sample, $\mu \mathrm{m}^{2} ; P_{0}$ is the atmospheric pressure, $10^{-1} \mathrm{MPa} ; Q_{0}$ is the flow rate of the gas in $P_{0}, \mathrm{~cm}^{3} \mathrm{~s}^{-1} ; \mu$ is viscosity of the gas, MPa.s; $L$ is the height of the coal sample, $\mathrm{cm} ; A$ is the sectional area of the coal sample, $\mathrm{cm}^{2} ; P_{1}$ is the inlet pressure, $10^{-1} \mathrm{MPa} ; P_{2}$ is the outlet pressure, $10^{-1} \mathrm{MPa}$.

According to the cyclic loading and unloading schemes, three groups of seepage tests were conducted, and the results are shown in Figure 4a. The mean of the three groups of data is taken as the permeability at each stress point in the figure.
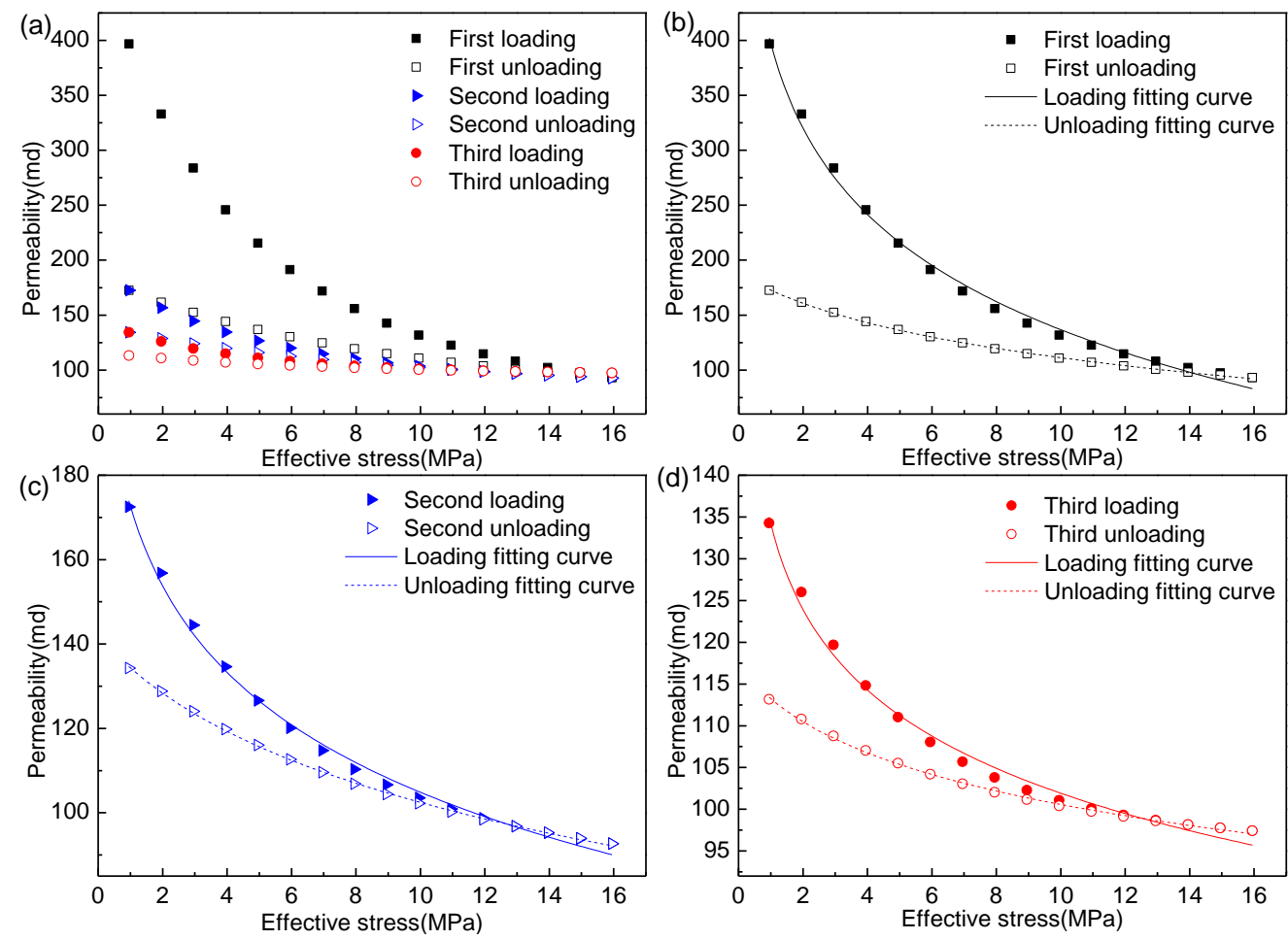

Figure 4. The test results and fitted curve showing the permeability and effective stress on broken coal samples under cyclic loading and unloading conditions: (a) the test result showing the permeability and effective stress on broken coal samples under cyclic loading and unloading conditions, (b) the fitted curve of permeability and effective stress during the first loading and unloading, (c) the fitted curve of permeability and effective stress during the second loading and unloading, (d) the fitted curve of permeability and effective stress during the third loading and unloading.

It can be seen from Figure 4a that during the loading stage, the permeability of broken coal samples gradually decreased with increasing effective stress while the rate of reduction thereof gradually decreased. During the unloading stage, the permeability of broken coal samples gradually increased with decreasing effective stress while the rate of increase gradually increased, therefore, during the cyclic loading and unloading of broken coal samples, the permeability showed a non-linear relationship with effective stress. By utilising a non-linear function, the test result between the permeability and 
effective stress on broken coal samples under cyclic loading and unloading conditions was fitted. The fitted curves are displayed in Figure $4 \mathrm{~b}-\mathrm{d}$ and the fitting equations are listed in Table 2. As shown, the permeability of coal samples was a logarithmic function of effective stress and the correlation coefficients of various fitted equations were all greater than 0.99 , implying that the test results were favourably consistent with the fitted results.

Table 2. The fitting equations of permeability and effective stress on broken coal samples under cyclic loading and unloading conditions.

\begin{tabular}{ccc}
\hline Test Status & $\begin{array}{c}\text { Fitting Equation of Permeability } \\
(\boldsymbol{K}) \text { and Effective Stress }\left(\boldsymbol{\sigma}_{\mathbf{1}}\right)\end{array}$ & Correlation Coefficients $\left(\boldsymbol{R}^{\mathbf{2}}\right)$ \\
\hline First loading & $K=403.2-115.4 \ln \left(\sigma_{1}+0.1\right)$ & 0.995 \\
First unloading & $K=237.7-49.8 \ln \left(\sigma_{1}+2.7\right)$ & 0.999 \\
Second loading & $K=180.2-32.4 \ln \left(\sigma_{1}+0.3\right)$ & 0.995 \\
Second unloading & $K=173.2-27.5 \ln \left(\sigma_{1}+3.1\right)$ & 0.999 \\
Third loading & $K=132.0-13.1 \ln \left(\sigma_{1}-0.2\right)$ & 0.990 \\
Third unloading & $K=121.5-8.5 \ln \left(\sigma_{1}+1.6\right)$ & 0.998 \\
\hline
\end{tabular}

\subsection{Particle Breakage and Distribution Law after Each Loading and Unloading Seepage Test}

After each loading and unloading seepage test, the broken coal samples were screened and weighed using sieves with the pore sizes of 1, 2.8, 4.6, 6.8, 10.2, 15.1 and $18.2 \mathrm{~mm}$, respectively. Afterwards, the mass and mass percentage of the coal samples with different particle sizes were recorded and calculated, as shown in Figure 5.
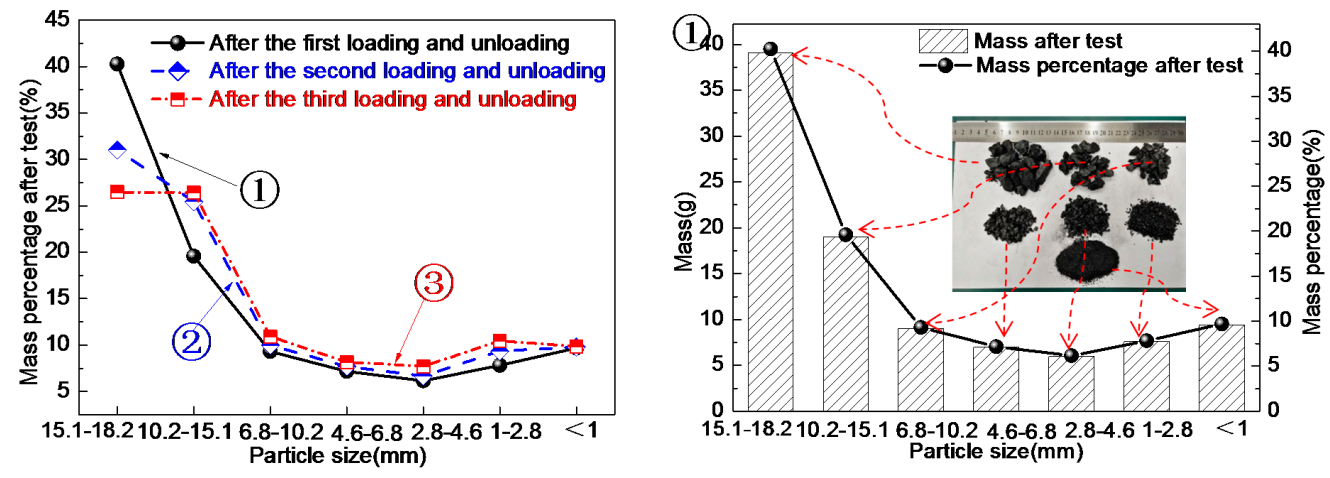

(a)

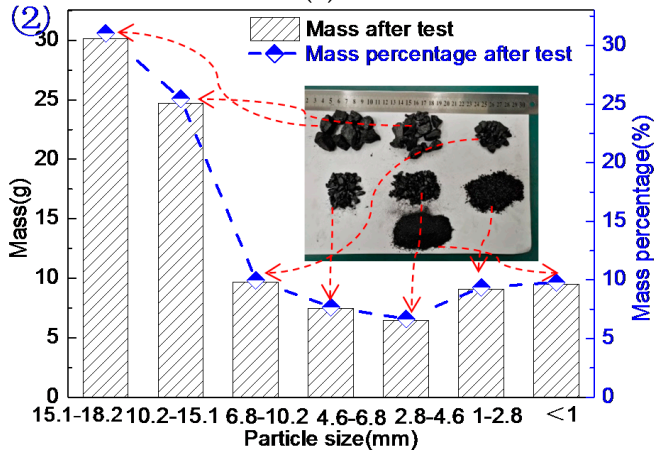

(c)

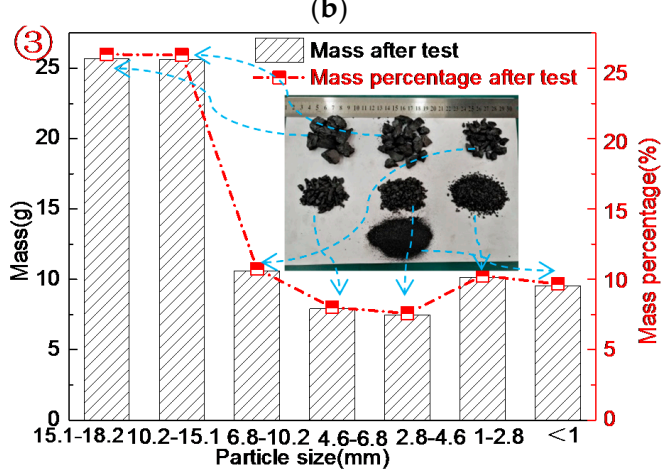

(d)

Figure 5. Mass and mass percentage of coal samples with different particle sizes after each loading and unloading seepage test: (a) mass percentage of coal samples with different particle sizes after each loading and unloading seepage test, (b) mass and mass percentage of coal samples with different particle sizes after the first loading and unloading seepage test, (c) mass and mass percentage of coal samples with different particle sizes after the second loading and unloading seepage test, (d) mass and mass percentage of coal samples with different particle sizes after the third loading and unloading seepage test. 
As shown in Figure 5, after the first loading and unloading seepage test, the broken coal sample with a particle size of 15.1-18.2 mm was crushed to form a mixture with multiple particle sizes due to its having been crushed during the test stage; the crushing amount was $59.74 \%$, which was calculated by dividing the crushing mass of the particles after the test by the original mass of the particles. In the mixture, the proportion of the original particle size mass was the largest, reaching $40.26 \%$, followed by the particle size (10.2-15.1 mm) mass produced by crushing, which was $19.60 \%$, and the smaller particle size mass produced by crushing accounted for a smaller proportion and the difference was not significant, which was approximately between $6 \%$ and $10 \%$. After the second loading and unloading seepage test, the particles with a particle size of 15.1-18.2 $\mathrm{mm}$ in the mixture were further crushed. The crushing amount was $9.21 \%$, the mass proportion of particle size of 15.1-18.2 mm decreased from $40.26 \%$ to $31.05 \%$. However, the proportion of other particles in the mixture increased. Among them, the mass proportion of the particle size of $10.2-15.1 \mathrm{~mm}$ increased the most, from $19.60 \%$ to $25.46 \%$, and the increase amount reached $5.86 \%$. The increase amount of the other smaller, crushed particles was small and the difference was not large; about $0.5 \%$ to $1 \%$. After the third loading and unloading seepage test, the particles with a particle size of 15.1-18.2 $\mathrm{mm}$ in the mixture were crushed again, with a crushing amount of $4.59 \%$, and the mass proportion of which decreased from $31.05 \%$ to $26.46 \%$. The mass proportion of other smaller particles in the mixture increased and the increase amount was small, between $0.5 \%$ and $1 \%$.

To sum up, the larger the particle size of a coal sample was, the greater the breakage probability and crushing amount of the particle will be after each loading and unloading seepage test. The major reasons for this are as follows: the larger particles probably contained more defects and their strength was generally lower than that of the smaller particles. Under the same stress, large particle damage probability and breakage amount were obviously greater. With the increase of cyclic loading and unloading times, the crushing amount of broken coal samples decreased gradually $(59.74 \%>9.21 \%>$ $4.59 \%$ ). The major reasons for this are as follows: with the increase of cyclic loading and unloading times, the particle size of the broken coal samples becomes smaller and smaller, and its equivalent elastic modulus keeps increasing, as shown in Figure 6, which was equivalent to the increase of strength, so its crushing amount becomes smaller and smaller.

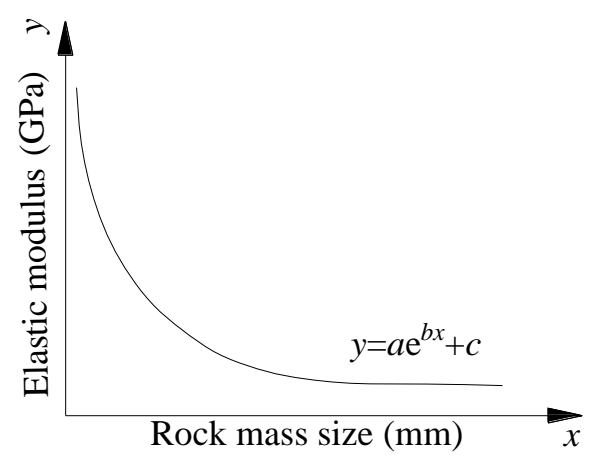

Figure 6. The correlation between rock mass size and elastic modulus [33].

According to the data of screened and weighed broken coal samples after each loading and unloading seepage test, the size gradation curve, as shown in Figure 7, before and after the seepage test of broken coal samples was drawn using mesh size as the $X$ coordinate and the sieving rate (calculated by dividing the mass of samples screened by a certain level of sieve by the total mass of samples) as the $\mathrm{Y}$ coordinate.

As can be seen from Figure 7, the size gradation curve of the broken coal sample after the seepage test shifted upwards compared with those before the test, which indicates that after the test, the coal sample particles were crushed, the content of fine particles increased, as shown in Figure 5, and the particle size gradation became better. In addition, with the increase of cyclic loading and unloading times of the broken coal sample, the particle size gradation of the broken coal sample gradually became 
better. The major reasons for this are as follows: with the increase of cyclic loading and unloading times, the crushing degree of coal sample particles increased gradually, and the content of fine particles produced gradually increased, as shown in Figure 5, thus leading to the gradual improvement of particle size grading.

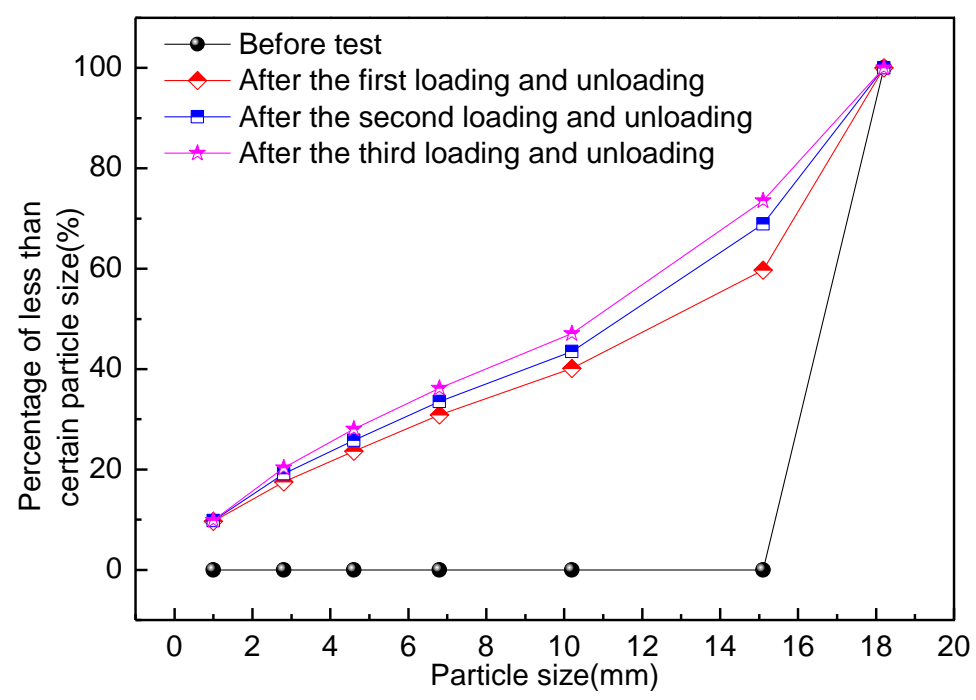

Figure 7. Size gradation curve before and after the seepage test of the broken coal sample.

\section{Results Analysis and Discussions}

\subsection{The Changes in Permeability}

To analyse the change law of the permeability of broken coal samples under cyclic loading and unloading conditions, the loss $\left(D_{1}\right)$ of permeability of coal samples during the loading stage, the recovery $\left(D_{2}\right)$ of permeability during the unloading stage and irreversible loss $\left(D_{3}\right)$ of permeability after the one loading and unloading cycle were defined. These parameters are expressed as follows:

$$
\begin{aligned}
& D_{1}=K_{1}-K_{a} \\
& D_{2}=K_{1}{ }^{\prime}-K^{\prime}{ }_{a} \\
& D_{3}=K_{1}-K_{1}{ }^{\prime}
\end{aligned}
$$

where, $K_{1}$ and $K_{a}$ refer to the permeabilities (md) of coal samples at the first and the last stress points during loading while $K_{\mathrm{a}}{ }^{\prime}$ and $K_{1}{ }^{\prime}$ denote the permeabilities (md) of coal samples at the first and the last stress points during unloading, respectively.

By separately substituting the test results of permeability of broken coal samples under cyclic loading and unloading conditions into Equations (2), (3) and (4), the values of $D_{1}, D_{2}$ and $D_{3}$ of coal

\begin{tabular}{|c|c|c|c|c|}
\hline Loading and Unloading & Test Status & $D_{1} / \mathrm{md}$ & $\mathrm{D}_{2} / \mathrm{md}$ & $D_{3} / \mathrm{md}$ \\
\hline \multirow{2}{*}{ First } & loading & 303.7 & - & \multirow{2}{*}{224.4} \\
\hline & unloading & - & 79.3 & \\
\hline \multirow{2}{*}{ Second } & loading & 79.8 & - & \multirow{2}{*}{38.2} \\
\hline & unloading & - & 41.6 & \\
\hline \multirow{2}{*}{ Third } & loading & 36.8 & - & \multirow{2}{*}{21.1} \\
\hline & unloading & - & 15.7 & \\
\hline
\end{tabular}
samples were calculated, as given in Table 3 and Figure 8.

Table 3. Calculated values of $D_{1}, D_{2}$ and $D_{3}$ of coal samples under cyclic loading and unloading conditions. 


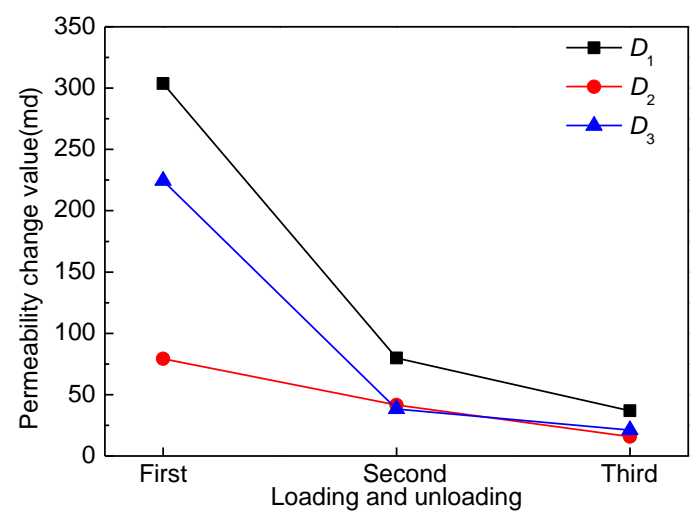

Figure 8. Relationship curve between $D_{1}, D_{2}$ and $D_{3}$ values of coal samples and cyclic loading and unloading times.

As shown in Table 3 and Figure 8, during three loading and unloading cycles, the losses $\left(D_{1}\right)$ of permeability of coal samples in the loading stage were 303.7, 79.8 and $36.8 \mathrm{md}$, while the recovery $\left(D_{2}\right)$ of permeability in the unloading stage were $79.3,41.6$ and $15.7 \mathrm{md}$, respectively. Moreover, the irreversible losses $\left(D_{3}\right)$ of permeability after each loading and unloading cycle were 224.4, 38.2 and $21.1 \mathrm{md}$, respectively. It can be seen that $D_{1}, D_{2}$ and $D_{3}$ gradually decreased with increasing cyclic loading and unloading events. During the three loading and unloading cycles, the losses $D_{1}(303.7$, 79.8 and $36.8 \mathrm{md}$ ) of permeability in the loading stage were far larger than the recoveries $D_{2}(79.3,41.6$ and $15.7 \mathrm{md}$ ) of permeability in the unloading stage in the same cycle. This indicated that during the same loading and unloading cycle, the loss $\left(D_{1}\right)$ of permeability of coal samples was much greater than the recovery $\left(D_{2}\right)$ of permeability in the unloading stage.

\subsection{Stress Sensitivity of Permeability}

To analyse the sensitivity of permeability of broken coal samples to the stress change under cyclic loading and unloading conditions, the stress sensitivity coefficient $\left(C_{K}\right)$ of the permeability was defined, which is calculated as follows:

$$
C_{K}=\left|\frac{\partial K}{\partial \sigma_{1}}\right| .
$$

By substituting the fitting formula shown in Table 2 into Equation (5), the relationship between the stress sensitivity of the permeability of broken coal samples and effective stress under cyclic loading and unloading conditions can be calculated, as shown in Figure 9.

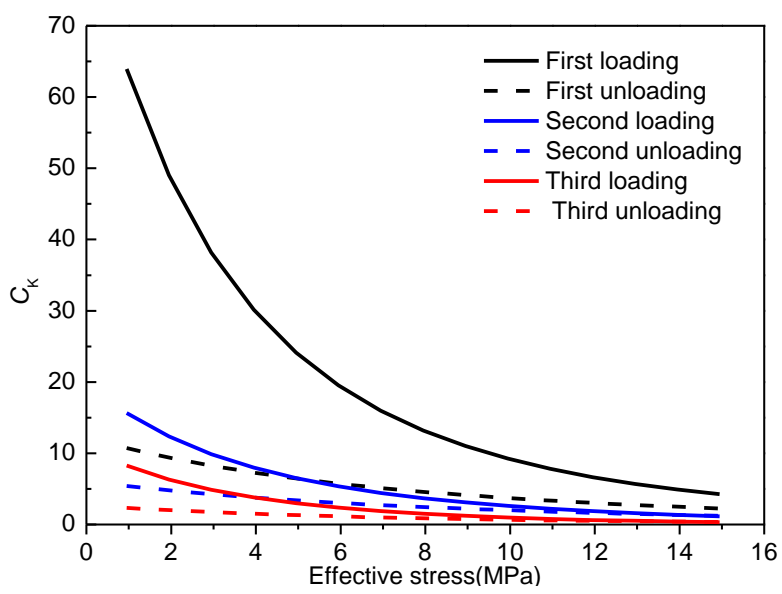

Figure 9. Stress sensitivity coefficients of permeability of broken coal samples under cyclic loading and unloading conditions. 
As shown in Figure 9, the stress sensitivity of permeability of broken coal samples gradually decreased with increasing effective stress during cyclic loading and unloading. Both in loading and unloading stages, the stress sensitivities of permeability of broken coal samples all gradually decreased with increased cyclic loading and unloading. During the same loading and unloading cycle, the stress sensitivity of permeability of coal samples in the loading stage was far higher than that in the unloading stage.

\subsection{Reasons for the Changes in Permeability under Cyclic Loading and Unloading Conditions}

As shown in Figure 10, the initial height of broken coal samples was recorded as $h_{0}$ and the compression-induced displacement recorded using the displacement transducer at the vertical direction during the triaxial seepage test was $\Delta h$. Therefore, the axial strain $(\varepsilon)$ on broken coal samples during the whole test can be calculated as follows:

$$
\varepsilon=\Delta h / h_{0} .
$$

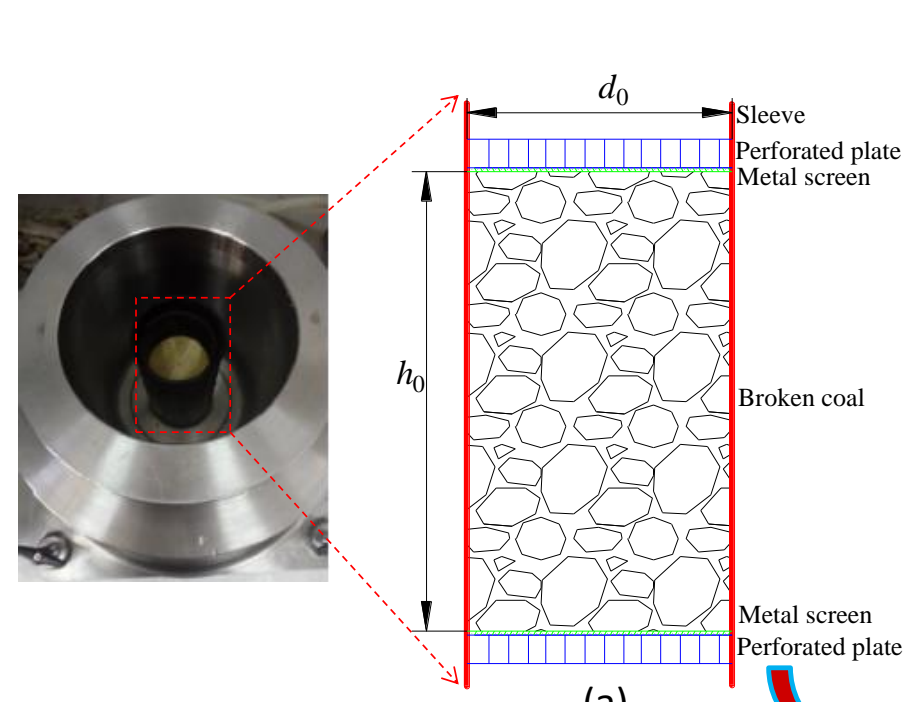

(a)

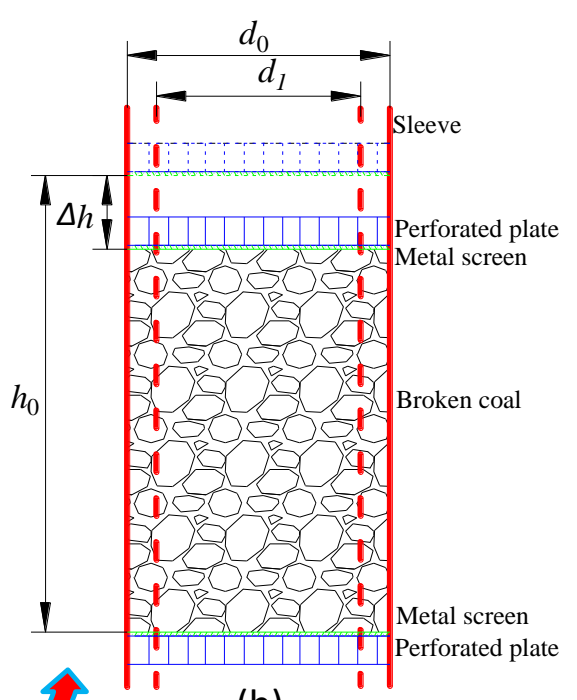

(b)

Figure 10. Calculation of strain and porosity: (a) before the seepage test (b) after the seepage test.

It was assumed that the true density of coal samples, the mass of broken coal samples during each test and the initial diameter of the colloid sleeve were $\rho, m$ and $d_{0}$, respectively. Owing to axial stress being equal to the confining stress throughout the test, that is, the sample was always in a hydrostatic-pressure state, it can be supposed that the radial strain on broken coal samples was equal to the axial strain. Therefore, the diameter $\left(d_{1}\right)$ of coal samples during triaxial loading can be expressed as follows:

$$
d_{1}=d_{0}(1-\varepsilon) .
$$

In accordance with Equations (6) and (7), and Figure 10b, it can be seen that the porosity $(\phi)$ of broken coal samples during the test can be calculated as follows:

$$
\phi=\frac{\frac{\pi}{4} d_{1}^{2}\left(h_{0}-\Delta h\right)-\frac{m}{\rho}}{\frac{\pi}{4} d_{1}^{2}\left(h_{0}-\Delta h\right)}=\frac{\pi \rho d_{0}^{2} h_{0}(1-\varepsilon)^{3}-4 m h_{0}^{2}}{\pi \rho d_{0}^{2} h_{0}(1-\varepsilon)^{3}} .
$$

By substituting the data during the test monitored by using the displacement transducer into Equation (6), the stress-strain curves of coal samples under cyclic loading and unloading were calculated and drawn, as shown in Figure 11. By substituting the calculated strain into Equation (8), 
the relationship curves between the porosity of coal samples and effective stress during cyclic loading and unloading are shown in Figure 12.

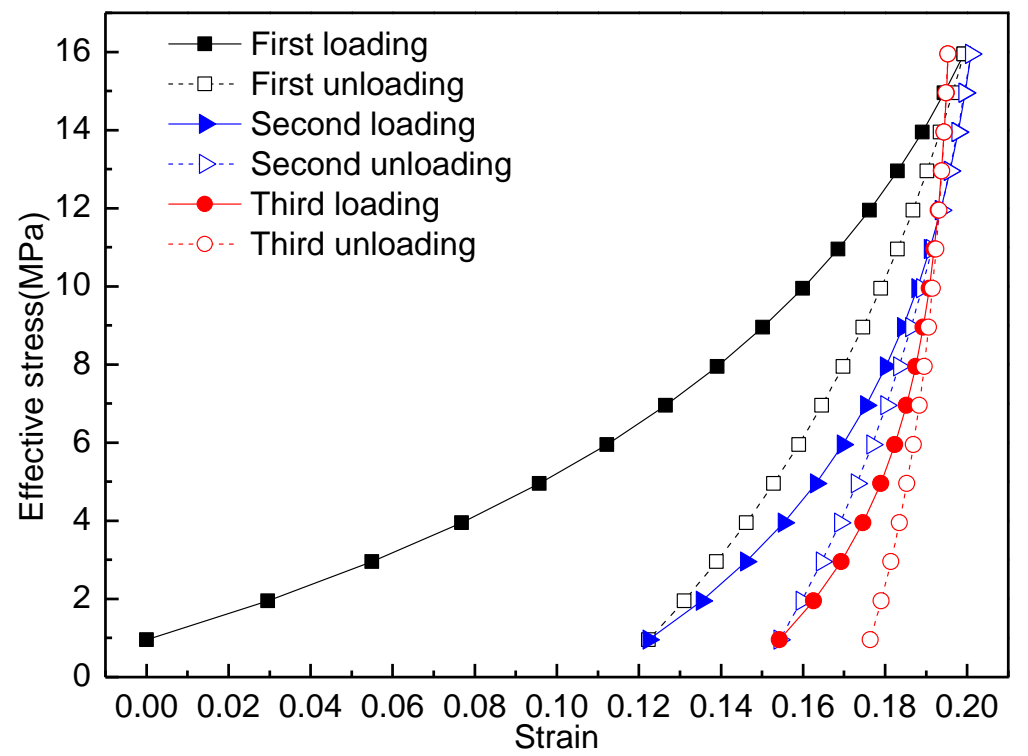

Figure 11. Stress-strain curves of coal samples under cyclic loading and unloading conditions.

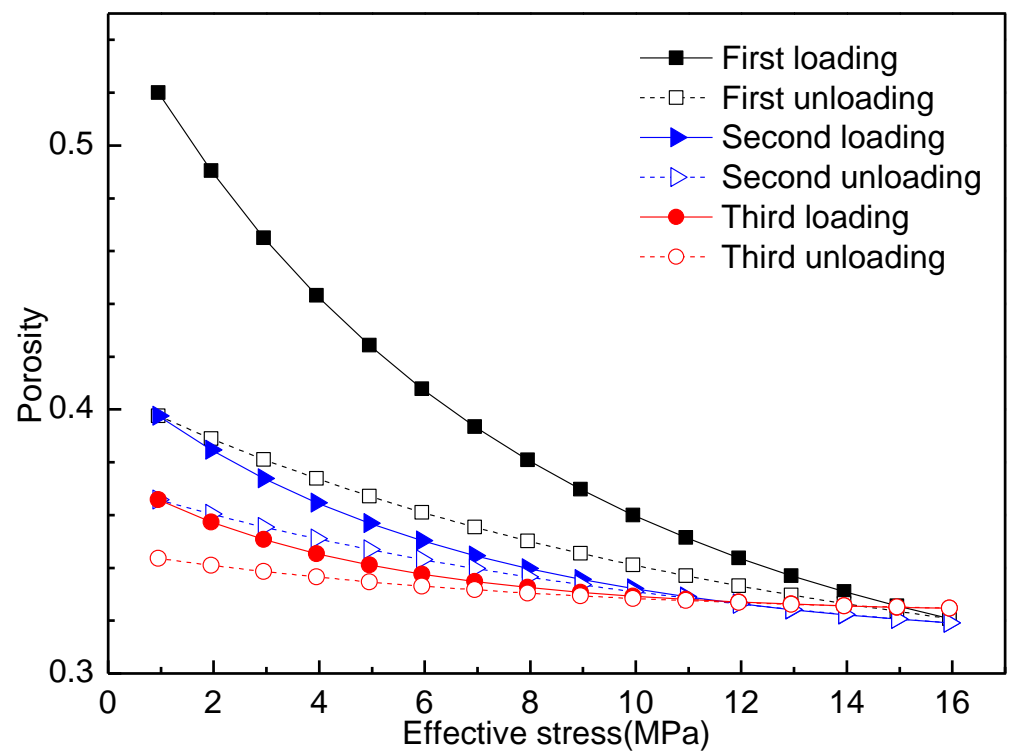

Figure 12. Changes of porosity of coal samples under cyclic loading and unloading conditions.

It can be seen from Figures 11 and 12 that the increments of strains on coal samples over three cycles were $0.199,0.079$ and 0.041 , respectively. Consequently, the corresponding reductions in the porosity were $0.198,0.078$ and 0.04 , respectively. It indicated that with the increased cyclic loading and unloading events, the reductions in the porosity of coal samples in the loading stage gradually decreased, thus leading to the gradual reduction in the loss of permeability of coal samples. The reduction amounts of strain on coal samples during three unloading events were 0.077, 0.047 and 0.019 , respectively, corresponding to increments of $0.076,0.046$ and 0.018 in porosity. This implied that with increasing loading and unloading cycles, the increment in the porosity of coal samples in the unloading stage gradually decreased, thus causing the recovery of permeability to decrease. During the three loading and unloading cycles, the reductions $(0.198,0.078$ and 0.04$)$ in the porosity of coal samples in the loading stage were much greater than the increments $(0.076,0.046$ and 0.018$)$ in the 
porosity of coal samples in the unloading stage within the same cycle. Therefore, during each loading and unloading cycle, the loss of permeability of coal samples in the loading stage was much greater than the recovery thereof in the unloading stage.

The reasons why the porosity of broken coal samples reduced in the loading stage involves three things [34]: (1) the structural re-arrangement of broken coal particles caused a significant reduction in porosity: in the early stage of loading of broken coal masses, there was no cohesion between particles to therefore cause slippage and rotation of particles. The particle structures were rearranged resulting in the significant reduction in porosity, which was the primary reason why broken coal masses were compacted and deformed. (2) Broken coal samples were crushed further and then the broken fine particles filled the void space, resulting in the further reduction of the porosity of the coal samples. (3) The compressive deformation between particles reduced the porosity: the compressive deformation was actually elastic deformation, which can be recovered in the unloading process. Figure 13 shows the porosity change of the broken coal sample during the loading stage. The first two factors caused a significant reduction in the porosity of coal samples, so they were the main reasons causing the reduction of porosity, and this portion of porosity of coal samples cannot be recovered during stress unloading. The reduction of porosity induced by the third factor can be recovered in the unloading process, which was the reason why the porosity of coal samples increased in the unloading stage, however, the influence of the third factor on the porosity was much less significant than those of the first two factors. Therefore, the main reason for the gradually reducing loss of permeability of coal samples in the loading stage with the increase of cyclic loading and unloading times is illustrated as follows: with the increase of cyclic loading and unloading events, the particles of broken coal samples were further crushed and their corresponding structural re-arrangement capability gradually weakened, resulting in the gradual reduction of the porosity (albeit by smaller amounts each time). The main reason why the recovery amount of permeability of coal samples in the unloading stage gradually decreased with the increase of cyclic loading and unloading cycles was that, with an increased number of loading and unloading cycles, some particles being subjected to compressive deformation were constantly crushed. As a result, the recovery after compressive deformation gradually decreased, consequently leading to a gradual reduction in the increment in the porosity. During each loading and unloading cycle, the loss of permeability in the loading stage was much greater than the recovery of permeability in the unloading stage. This was mainly because the influence of structural rearrangement and breakage of particles in the loading stage on the porosity of coal samples was much greater than that of the recovery of particles after compressive deformation in the unloading stage on the porosity.

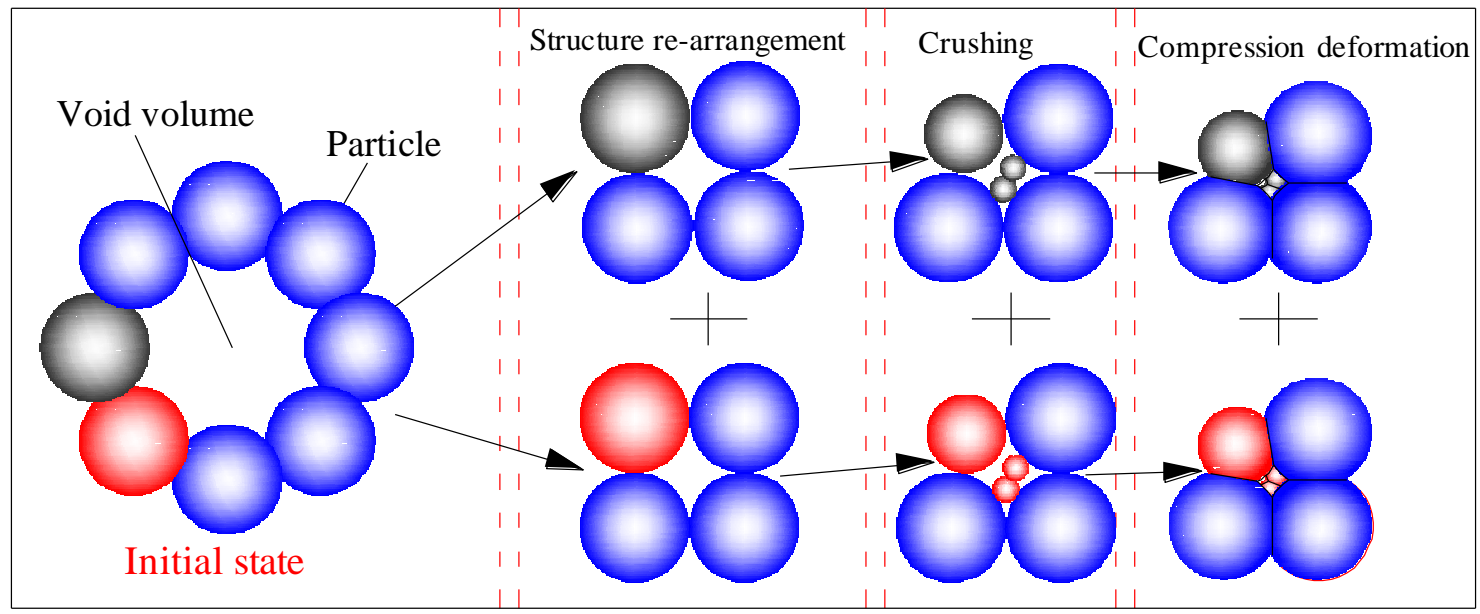

Figure 13. Schematic diagram of porosity change of broken coal samples during the loading stage. 


\subsection{The Relationship between Permeability and Strain, Porosity under Cyclic Loading and Unloading Conditions}

Based on permeability, strain and porosity data, the scatter diagrams between permeability and strain of broken coal samples were drawn and fitted to thus obtain the fitting curves between permeability and strain under cyclic loading and unloading conditions of broken coal samples, as shown in Figure 14. Besides, the scatter diagrams between permeability and porosity of broken coal samples were also drawn and fitted to thus obtain the fitting curves between permeability and porosity under cyclic loading and unloading conditions of broken coal samples, as shown in Figure 15.
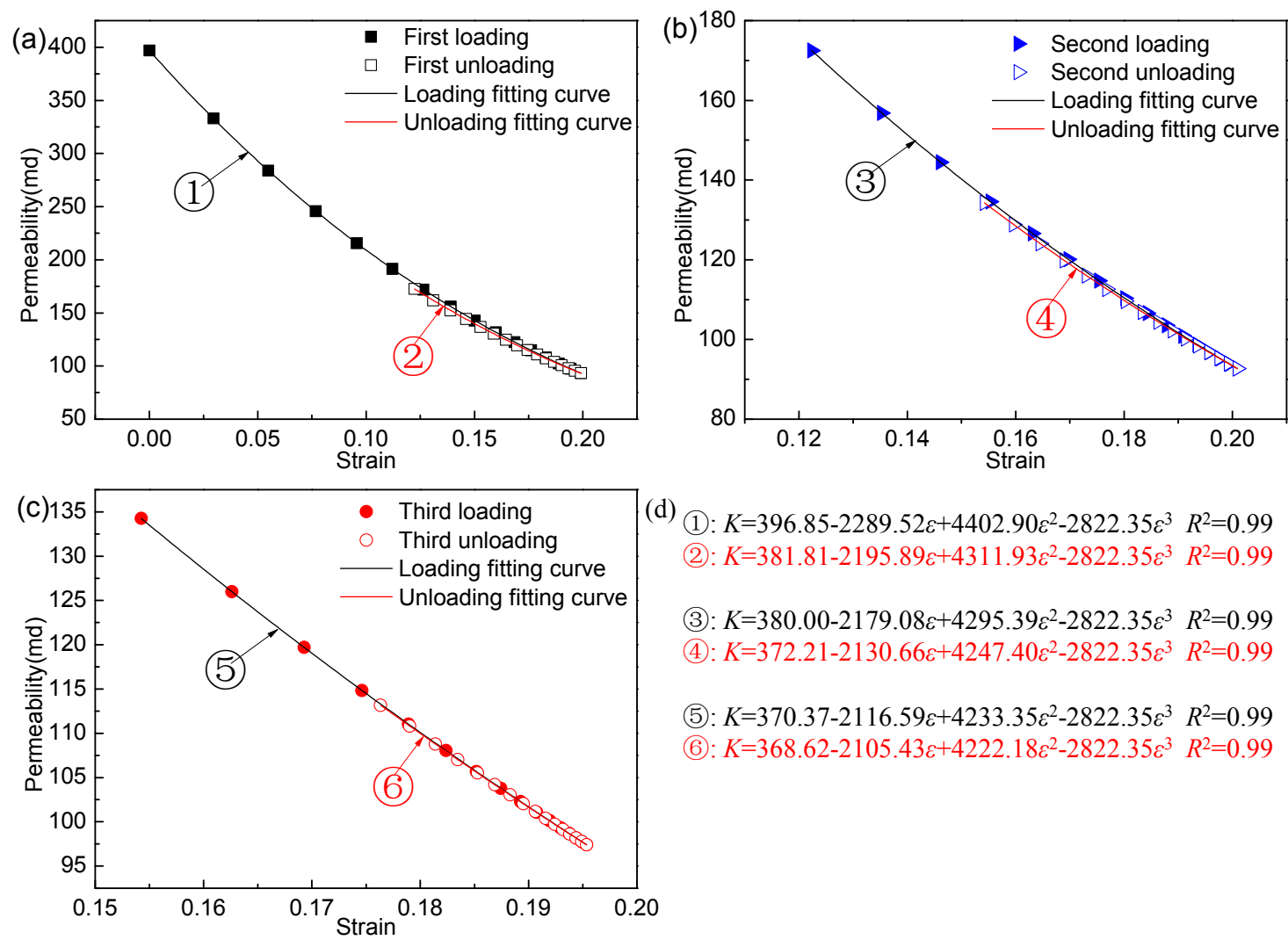

(d) (1): $K=396.85-2289.52 \varepsilon+4402.90 \varepsilon^{2}-2822.35 \varepsilon^{3} \quad R^{2}=0.99$

(2): $K=381.81-2195.89 \varepsilon+4311.93 \varepsilon^{2}-2822.35 \varepsilon^{3} \quad R^{2}=0.99$

(3): $K=380.00-2179.08 \varepsilon+4295.39 \varepsilon^{2}-2822.35 \varepsilon^{3} \quad R^{2}=0.99$

(4): $K=372.21-2130.66 \varepsilon+4247.40 \varepsilon^{2}-2822.35 \varepsilon^{3} \quad R^{2}=0.99$

(5): $K=370.37-2116.59 \varepsilon+4233.35 \varepsilon^{2}-2822.35 \varepsilon^{3} \quad R^{2}=0.99$

(6): $K=368.62-2105.43 \varepsilon+4222.18 \varepsilon^{2}-2822.35 \varepsilon^{3} \quad R^{2}=0.99$

Figure 14. Relation curve between permeability and strain under cyclic loading and unloading conditions of broken coal samples: (a) the first cyclic loading and unloading, (b) the second cyclic loading and unloading, (c) the third cyclic loading and unloading, (d) the fitting formulas between permeability and strain.

It can be speculated from Figures 14 and 15 that the permeability of broken coal samples decreased with increasing strain and increased with the increasing of porosity of the broken coal samples. The fitting curves between permeability and strain, and porosity are a cubic function and power function, respectively, and the fitting correlation coefficient of two functions was 0.99 . In addition, under the same strain or porosity, the permeability of the broken coal sample at the loading stage in each loading and unloading stage was the same as that at the unloading stage. This indicates that as long as the porosity of the broken coal sample is same during each loading and unloading (Equation (8) shows that strain and porosity are equivalent), the permeability of the broken coal sample is the same, independent of the stress state of the broken coal sample at that time. For example, it can be seen from Figures 11 and 12 that in each loading and unloading process, when the strain or porosity at the loading stage was equal to the strain or porosity at the unloading stage, the effective stress at the loading stage was greater than the effective stress at the unloading stage. At this time, the stress states of the broken coal samples at the loading stage and unloading stage were different, 
but the permeability was the same. Therefore, the permeability of broken coal samples under cyclic loading and unloading conditions was determined by its porosity, which conforms to the cubic law. The relationship between permeability and porosity is as follows [35,36]:

$$
\frac{K}{K_{0}}=\left(\frac{\phi}{\phi_{0}}\right)^{\alpha}
$$

where $\alpha$ is the porosity sensitive exponent; $K_{0}$ and $\phi_{0}$ are the initial permeability and porosity, respectively.
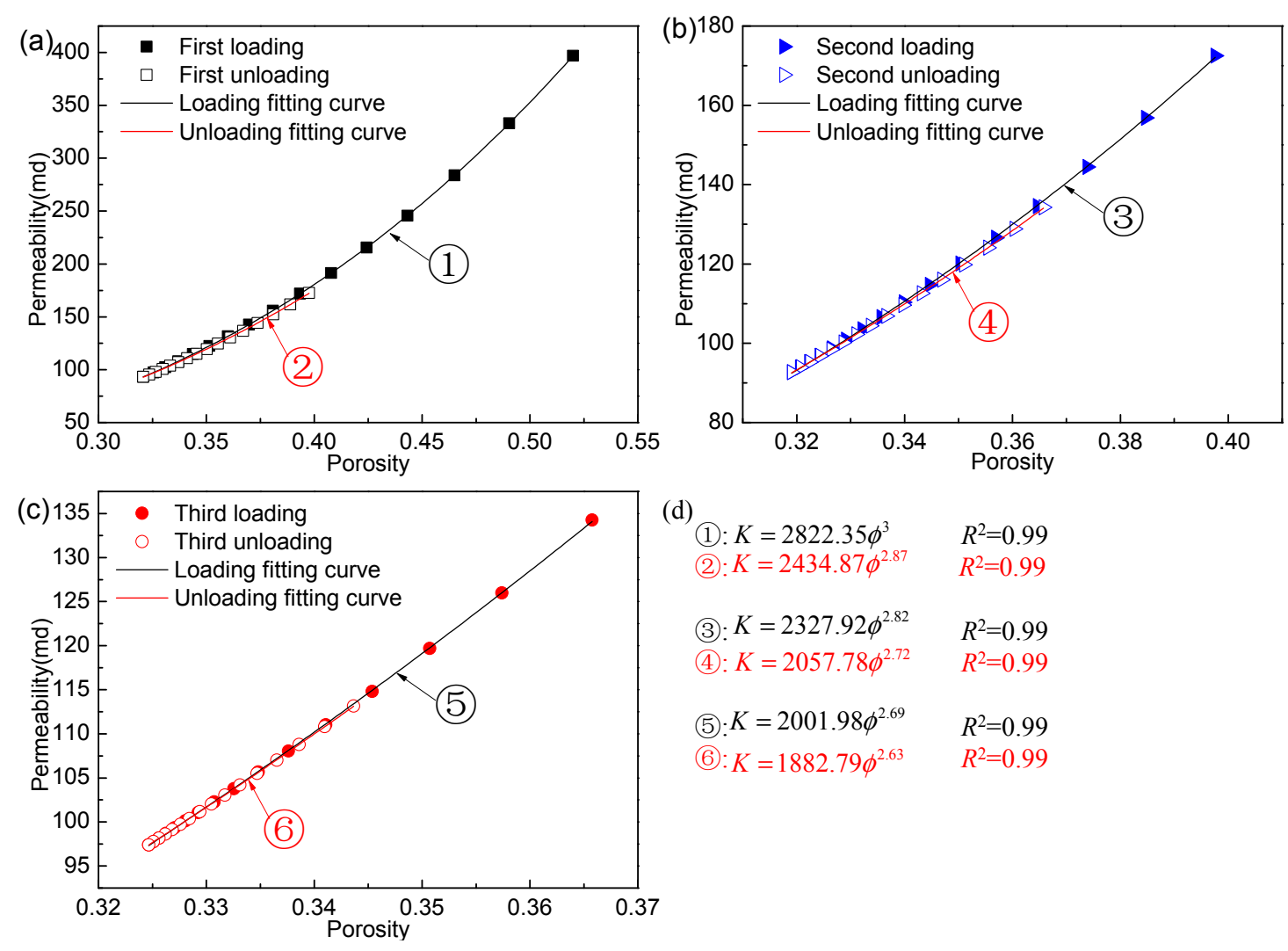

(d)
$\begin{array}{ll}\text { (1): } K=2822.35 \phi^{3} & R^{2}=0.99 \\ \text { (2): } K=2434.87 \phi^{2.87} & R^{2}=0.99\end{array}$
(3): $K=2327.92 \phi^{2.82} \quad R^{2}=0.99$
(4): $K=2057.78 \phi^{2.72} \quad R^{2}=0.99$
(5) $: K=2001.98 \phi^{2.69} \quad R^{2}=0.99$
(6): $K=1882.79 \phi^{2.63} \quad R^{2}=0.99$

Figure 15. Relation curve between permeability and porosity under cyclic loading and unloading conditions of broken coal samples: (a) the first cyclic loading and unloading, (b) the second cyclic loading and unloading, (c) the third cyclic loading and unloading, (d) the fitting formulas between permeability and porosity.

It can be seen from Figure 15 that the porosity sensitive exponent of the permeability and porosity fitting formula in three loading stages is 3,2.82 and 2.69, respectively. The porosity sensitive exponent of the permeability and porosity fitting formula in three unloading stages was 2.87, 2.72 and 2.63, respectively. It indicates that both in loading and unloading stages, the porosity sensitive exponent of broken coal samples all gradually decreased with increased cyclic loading and unloading (loading stage: $3>2.82>2.69$; unloading stage: $2.87>2.72>2.63$ ). During the same loading and unloading cycle, the porosity sensitive exponent of coal samples in the loading stage was higher than that in the unloading stage (first loading and unloading: $3>2.87$; second loading and unloading: $2.82>2.72$; third loading and unloading: $2.69>2.63$ ). Therefore, this further verifies the above analysis results: Both in loading and unloading stages, the stress sensitivities of permeability of broken coal samples all gradually decreased with increased cyclic loading and unloading. During the same loading and unloading cycle, the stress sensitivity of permeability of coal samples in the loading stage was far higher than that in the unloading stage. 


\section{Conclusions}

In this work, by applying a seepage test system for damaged coal-rock masses, seepage tests were carried out on the broken coal mass under cyclic loading and unloading conditions. First of all, the permeability evolution law of broken coal samples under cyclic loading and unloading conditions was obtained, and the sensitivity of permeability of broken coal samples was also analysed. Afterwards, the particle breakage and distribution law after each loading and unloading seepage test was analysed. Finally, the reasons for the changes in permeability of broken coal samples under cyclic loading and unloading conditions was revealed, and the relationship between permeability and strain, and porosity under cyclic loading and unloading conditions was discussed. The specific conclusions are shown as follows:

(1) The relationship between the permeability of broken coal samples and effective stress during cyclic loading and unloading conformed to a logarithmic function model. Moreover, the fitting equations for the permeability of coal samples and effective stress under various loading and unloading conditions were attained.

(2) The loss $\left(D_{1}\right)$ of permeability of broken coal samples in the loading stage, the recovery $\left(D_{2}\right)$ of permeability in the unloading stage and irreversible loss $\left(D_{3}\right)$ of permeability after one loading and unloading cycle all gradually decreased with increased numbers of cyclic loading and unloading events. During the same loading and unloading cycle, the loss $\left(D_{1}\right)$ of permeability in the loading stage was much greater than the recovery $\left(D_{2}\right)$ of permeability in the unloading stage.

(3) The stress sensitivity of permeability of broken coal samples gradually decreased with increased numbers of loading and unloading cycles. During the same loading and unloading cycle, the stress sensitivity of permeability of coal samples in the loading stage was much greater than that in the unloading stage.

(4) The larger the particle size of the coal sample is, the greater the breakage probability and crushing amount of the particle will be after each loading and unloading seepage test. With the increase of cyclic loading and unloading times, the crushing amount of the broken coal sample decreased gradually, but the particle size gradation of the broken coal sample gradually became better.

(5) Rearrangement, breakage and compressive deformation of coal particles in the loading stage can cause a significant decrease in the porosity of coal samples, thus resulting in a decreased permeability thereof. In the unloading stage, only the loss of permeability resulting from particle deformation could be recovered.

(6) The permeability of broken coal samples decreased with increasing strain and increased with the increasing of porosity of the broken coal samples. The fitting curves between permeability and strain, and porosity are a cubic function and power function, respectively. Besides, the permeability of broken coal samples under cyclic loading and unloading conditions was determined by its porosity, which conforms to the cubic law.

Author Contributions: Data curation, B.L.; Funding acquisition, Y.L.; Methodology, Y.L.; Validation, Q.Z.; Writing—original draft, B.L.; Writing—review \& editing, Q.Z.

Funding: This work is financially supported by the National Science and Technology Major Project of China (Grant No. 2016ZX05043005), the National Natural Science Foundation of China (51674050 and 51704046), the State Key Research Development Program of China (Grant No. 2016YFC0801404 and 2016YFC0801402), and the Fundamental Research Funds for the Central Universities (2018CDQYZH0001) which are gratefully acknowledged.

Conflicts of Interest: The authors declare no conflict of interest.

\section{References}

1. Liu, L.; Zhou, F.B. A comprehensive hazard evaluation system for spontaneous combustion of coal in underground mining. Int. J. Coal Geol. 2010, 82, 27-36.

2. Wang, H.; Dlugogorski, B.Z.; Kennedy, E.M. Coal oxidation at low temperatures: oxygen consumption, oxidation products, reaction mechanism and kinetic modelling. Prog. Energy Combust. 2003, 29, 487-513. [CrossRef] 
3. Zhang, Y.T.; Shi, X.Q.; Li, Y.Q.; Liu, Y.R.; Li, S.S.; Huang, Y. Mechanism and inhibiting effects of environmental-friendly inhibitor on coal spontaneous combustion. J. China Univ. Min. Technol. 2018, 47, 1224-1232.

4. Yuan, L.; Smith, A.C. Numerical study on effects of coal properties on spontaneous heating in longwall gob areas. Fuel 2008, 87, 3409-3419. [CrossRef]

5. Wang, F.; Ren, T.; Tu, S.; Hungerford, F.; Aziz, N. Implementation of underground longhole directional drilling technology for greenhouse gas mitigation in Chinese coal mines. Int. J. Greenh. Gas Con. 2012, 11, 290-303. [CrossRef]

6. Lin, B.; Liu, T.; Yang, W. Solid-gas coupling model for coalseams based on dynamic diffusion and its application. J. Chin. Univ. Min. Technol. 2018, 47, 32-39.

7. Song, Z.; Zhu, H.; Jia, G.; He, C. Comprehensive evaluation on self-ignition risks of coal stockpiles using fuzzy AHP approaches. J. Loss Prev. Process Ind. 2014, 32, 78-94. [CrossRef]

8. Yang, Y.; Li, Z.; Si, L.; Li, J.; Qin, B.; Li, Z. SOM's effect on coal spontaneous combustion and its inhibition efficiency. Combust. Sci. Technol. 2017, 189, 1-18. [CrossRef]

9. Liu, T.; Lin, B.Q.; Yang, W. Impact of matrix-fracture interactions on coal permeability: Model development and analysis. Fuel 2017, 207, 522-532. [CrossRef]

10. Kong, S.; Cheng, Y.; Ren, T.; Liu, H. A sequential approach to control gas for the extraction of multi-gassy coal seams from traditional gas well drainage to mining-induced stress relief. Appl. Energ. 2014, 131, 67-78. [CrossRef]

11. Wu, Y.; Pan, Z.; Zhang, D.; Lu, Z.; Connell, L.D. Evaluation of gas production from multiple coal seams: A simulation study and economics. Int. J. Min. Sci. Tech. 2018, 28, 359-371. [CrossRef]

12. Chang, X.; Tian, H. Technical scheme and application of pressure-relief gas extraction in multi-coal seam mining region. Int. J. Min. Sci. Tech. 2018, 28, 483-489.

13. Zou, Q.; Lin, B. Fluid-solid coupling characteristics of gas-bearing coal subject to hydraulic slotting: An experimental investigation. Energy Fuel 2018, 32, 1047-1060. [CrossRef]

14. Zou, Q.; Lin, B.; Zheng, C.; Hao, Z.; Zhai, C.; Liu, T.; Liang, J.; Yan, F.; Yang, W.; Zhu, C. Novel integrated techniques of drilling-slotting-separation-sealing for enhanced coal bed methane recovery in underground coal mines. J. Nat. Gas Sci. Eng. 2015, 26, 960-973. [CrossRef]

15. Zou, Q.; Lin, B.; Liu, T.; Zhou, Y.; Zhang, Z.; Yan, F. Variation of methane adsorption property of coal after the treatment of hydraulic slotting and methane pre-drainage: a case study. J. Nat. Gas Sci. Eng. 2014, 20, 396-406. [CrossRef]

16. Zhang, C.; Tu, S.; Zhang, L.; Wang, F.; Bai, Q.; Tu, H. The numerical simulation of permeability rules in protective seam mining. Int. J. Oil. Gas. Coal. T. 2016, 13, 243-259. [CrossRef]

17. Zhang, L.; Zhang, H.; Guo, H. A case study of gas drainage to low permeability coal seam. Int. J. Min. Sci. Tech. 2017, 27, 687-692. [CrossRef]

18. Liu, T.; Lin, B.Q.; Yang, W.; Zou, Q.L.; Kong, J.; Yan, F.Z. Cracking Process and Stress Field Evolution in Specimen Containing Combined Flaw Under Uniaxial Compression. Rock Mech. Rock Eng. 2016, 49, 3095-3113. [CrossRef]

19. Zhang, C.; Tu, S.; Zhang, L.; Bai, Q.; Yuan, Y.; Wang, F. A methodology for determining the evolution law of gob permeability and its distributions in longwall coal mines. J. Geophys. Eng. 2016, 13, 181-193. [CrossRef]

20. Zhang, C.; Tu, S.; Bai, Q.; Yang, G.; Zhang, L. Evaluating pressure-relief mining performances based on surface gas venthole extraction data in longwall coal mines. J. Nat. Gas. Sci. Eng. 2015, 24, 431-440. [CrossRef]

21. Whittles, D.N.; Lowndes, I.S.; Kingman, S.W.; Yates, C.; Jobling, S. Influence of geotechnical factors on gas flow experienced in a UK longwall coal mine panel. Int. J. Rock. Mech. Min. Sci. 2006, 43, 369-387. [CrossRef]

22. Wendt, M.; Balusu, R. CFD modeling of longwall goaf gas flow dynamics. Coal Saf. 2002, 20, 35-45.

23. Esterhuizen, G.; Karacan, C. Development of Numerical Models to Investigate Permeability Changes and Gas Emission around Longwall Mining Panel. In Proceedings of the 40th U.S. Symposium on Rock Mechanics (USRMS), Anchorage, AK, USA, 25-29 June 2005.

24. Jozefowicz, R.R. The Post-Failure Stress-Permeability Behaviour of Coal Measure Rocks. Available online: https: / / ethos.bl.uk/OrderDetails.do?uin=uk.bl.ethos.339717 (accessed on 28 December 2018).

25. Li, X.Y.; Logan, B.E. Permeability of fractal aggregates. Water Res. 2001, 35, 3373-3380. [CrossRef] 
26. Fan, L.; Liu, S. A conceptual model to characterize and model compaction behavior and permeability evolution of broken rock mass in coal mine gobs. Int. J. Coal. Geol. 2017, 172, 60-70. [CrossRef]

27. Karacan, C.Ö. Prediction of porosity and permeability of caved zone in longwall gobs. Transp. Porous Media 2010, 82, 413-439. [CrossRef]

28. Chu, T.; Yu, M.; Jiang, D. Experimental investigation on the permeability evolution of compacted broken coal. Transp. Porous Media 2016, 116, 1-22. [CrossRef]

29. Zhang, C.; Tu, S.; Zhang, L. Analysis of broken coal permeability evolution under cyclic loading and unloading conditions by the model based on the hertz contact deformation principle. Transp. Porous Media 2017, 119, 1-16. [CrossRef]

30. Ma, D.; Miao, X.X.; Jiang, G.H.; Bai, H.B.; Chen, Z.Q. An experimental investigation of permeability measurement of water flow in crushed rocks. Transp. Porous Media 2014, 105, 571-595. [CrossRef]

31. Miao, X.; Li, S.; Chen, Z.; Liu, W. Experimental study of seepage properties of broken sandstone under different porosities. Transp. Porous Media 2011, 86, 805-814. [CrossRef]

32. Li, Z.; Feng, G.; Jiang, H.; Shengyong, H.; Cui, J.; Song, C.; Gao, Q.; Qi, T.; Guo, X.; Li, C.; et al. The correlation between crushed coal porosity and permeability under various methane pressure gradients: a case study using Jincheng anthracite. Greenhouse Gases Sci. Technol. 2018, 8, 493-509. [CrossRef]

33. Jialai, W.; Hongwei, Z. Study on Size Effect of Young's Modulus for Rock. Available online: http:/ / en.cnki. com.cn/Article_en/CJFDTOTAL-YTLX199801010.htm (accessed on 28 December 2018).

34. Zhang, C.; Zhang, L.; Tu, S.; Hao, D.; Teng, T. Experimental and numerical study of the influence of gas pressure on gas permeability in pressure relief gas drainage. Transp. Porous Media 2018, 124, 1-21. [CrossRef]

35. David, C.; Wong, T.F.; Zhu, W.; Zhang, J. Laboratory measurement of compaction-induced permeability change in porous rocks: implications for the generation and maintenance of pore pressure excess in the crust. Pure Appl. Geophys. 1994, 143, 425-456. [CrossRef]

36. Ghabezloo, S.; Sulem, J.; Saint-Marc, J. Evaluation of a permeability-porosity relationship in a low-permeability creeping material using a single transient test. Int. J. Rock Mech. Min. Sci. 2009, 46, 761-768. [CrossRef] 